\title{
BOUVERET'S SYNDROME: A CHALLENGING CASE OF GASTRIC OUTLET OBSTRUCTION.
}

1. MBBS

House Officer Surgery $\mathrm{CMH}$ Multan.

2. MBBS

Resident General Surgery Combined Military Hospital Multan.

3. FCPS (General Surgery)

Assistant Professor General Surgery Classified Surgical Specialist

General Surgery

Combined Military Hospital, Multan.

Correspondence Address:

Dr. Irfan Qadir

House No. 3821-8D, Tippu Sultan

Colony,

Near Old Sabzi Mandi, Multan.

irfanqadir88@gmail.com

Article received on:

03/07/2019

Accepted for publication:

$14 / 10 / 2019$

\begin{abstract}
Marrium Gul', Irfan Qadir ${ }^{2}$, Muhammad Qasim Butt ${ }^{3}$
\end{abstract}
ABSTRACT... Bouveret's syndrome causes gastric outlet obstruction when a gallstone is impacted in the duodenum or stomach via a bilioenteric fistula. We present case of a 40-year-old female presented with epigastric pain and intractable vomiting for 2 days. Her physical examination and laboratory workup including blood analysis, amylase test and lipase test were normal. Plain abdominal X-ray did not show any signs of small bowel obstruction. A nasogastric tube was placed and drained $2.5 \mathrm{~L}$ of gastric contents immediately. Esophagogastroduodenoscopy showed a dilated stomach with excessive secretions and a large blackish-brown hard stone in the duodenal bulb. After failed attempt at endoscopic extraction, patient underwent laparotomy and removal of stone via duodenal incision. Subsequently, the patient exhibited a good postoperative recovery. The condition of the patient has remained stable after being followed up for one year.

Key words: $\quad$ Bouveret's Syndrome, Cholelithiasis, Gastric Outlet Obstruction, Gall Bladder, Pakistan.

Article Citation: Gul M, Qadir I, Butt MQ. Bouveret's syndrome: A challenging case of gastric outlet obstruction. Professional Med J 2020; 27(6):1316-1319. DOI: 10.29309/TPMJ/2020.27.06.3894

\section{INTRODUCTION}

Bouveret syndrome is a rare form of gallstone induced lleus accounting for only $1-3 \%$ of cases. $^{1,2}$ It is caused by the passage of a large gallstone through a cholecysto-duodenal fistula and impaction into the duodenum, resulting in gastric outlet obstruction with epigastric pain and postprandial vomiting. ${ }^{3}$ Until 2008 , up to 300 cases had been reported in the world literature. ${ }^{4}$ Despite advancements in diagnostics and intensive care facilities morbidity and mortality rates still remain high, estimated at $60 \%$ and $12 \%-30 \%$ respectively. Advanced age and associated comorbidities are major adverse prognostic factors. ${ }^{4,5}$ We present a case of Bouveret syndrome in a young otherwise healthy female with successful surgical management following endoscopic treatment failure, followed by a review of the literature.

\section{Case Presentation}

A 40-year-old female was admitted in the gastroenterology service with complaints of intractable vomiting for two days. She also reported progressively increasing upper abdominal pain and vomiting over last one month. Nausea and vomiting frequently occurred after meals. However, patient denied any history of fever, jaundice, melena or hematemesis. Laboratory workup, including blood analysis, liver function test, amylase test and lipase test, done in the outpatient department were normal. Past history was significant for acute cholecystitis one year back which was managed conservatively.

Physical examination was significant for mild tenderness in the epigastric area. Bowel sounds were normal. Plain abdominal X-ray did not show any signs of small bowel obstruction. A nasogastric tube was placed and drained 2.5 $\mathrm{L}$ of gastric contents immediately. Intravenous antibiotics and proton pump inhibitor therapy were started.

Esophagogastroduodenoscopy was done next day which revealed a normal esophagus and a dilated stomach with excessive secretions. A large blackish-brown hard stone was observed 
in the duodenal bulb. Endoscopic retrieval of the gallstone using a basket and mechanical lithotripsy was unsuccessful. Patient was thereafter referred to general surgery service.

Upper midline laparotomy was done. During the operation, multiple adhesions among the gallbladder, duodenal bulb and omentum were observed. Gall bladder was contracted and shriveled. Palpation for second part of duodenum revealed a large hard stone inside the duodenum. Subsequently, stone removal was done via duodenal incision, primary repair of duodenum and placement of drain into hepato-renal pouch.
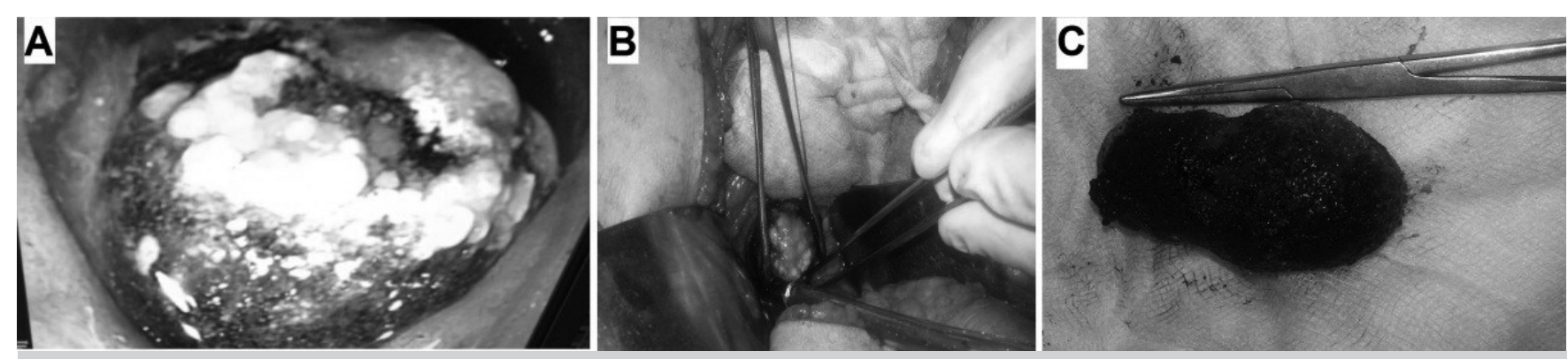

Figure-1.

A: EGD showing stone in second part of duodenum

B: Intra-operative picture of stone being retrieved from duodenum

C: Pear shaped stone after removal

Post operatively, patient was managed with IV fluids, antibiotics and kept NPO. Oral diet was started on third post-operative day and progressed gradually. She was discharged on fourth post-operative day and remains symptom free during 1 year follow up.

\section{DISCUSSION}

For optimal outcome of Bouveret's syndrome, a prompt diagnosis is required given the high incidence of co-morbidities in affected patient population. Clinically, patients present with gastric outlet obstruction, with predominant symptoms of nausea, postprandial vomiting, and epigastric pain. ${ }^{3}$ The major risk factors for developing this syndrome include advanced age (more than 70 years), female gender, gallstones larger than 2.5 $\mathrm{cm}$ and postsurgical altered $\mathrm{Gl}$ anatomy. ${ }^{6,7}$

Initial investigation of choice would be an abdominal radiograph; however, the classic Rigler's triad (pneumobilia, SBO and gallstone) has only been reported $30-35 \%$ of cases. Ultrasound can be helpful to show biliary pathology, however contrast enhanced CT is ultimately required to confirm the diagnosis of obstruction and stone. It has a high sensitivity (93\%), specificity (100\%) and accuracy (99\%) according to $\mathrm{Yu}$ et al. ${ }^{8}$ In recent years, magnetic resonance cholangiopancreatography has proved efficacious in diagnosing this condition. ${ }^{3}$ Esophagogastroduodenoscopy may be performed for both diagnostic and therapeutic purposes. However, the ability to remove impacted gallstones endoscopically is still limited. ${ }^{9}$

The optimal treatment for Bouveret's syndrome remains controversial; options include endoscopic treatment, extracorporeal shockwave lithotripsy, intracorporeal electrohydraulic lithotripsy, open or laparoscopic surgery. ${ }^{10}$ Before embarking on any treatment strategy, parameters such as patient's age, comorbidities, general condition, the location of the obstruction, the size of the stone and fistula should be taken into consideration. ${ }^{4,5}$

Endoscopic or percutaneous approaches should always be attempted prior to surgery, as most of the patients are likely be poor surgical candidates. ${ }^{10,11}$ However, despite some reports of success, $91 \%$ of patients will have to undergo surgery for definitive treatment. ${ }^{11,12}$

Choice of procedure includes single stage surgery (refers to a combination of enterolithotomy plus cholecystectomy and fistula repair), a two stage 
procedure (enterolithotomy and stone retrieval initially with cholecystectomy and fistula repair at a later date) or simple extraction of the stone without fistula repair. ${ }^{1}$ Single stage surgery is usually preferred in selected low-risk patients with a mortality of $20 \%$ to $30 \%$. In critically ill patients a two-stage approach may be adopted. This approach carries a $5 \%$ risk of recurrence of gallstone ileus before the second stage and a reported mortality of $12 \% .4,5,13$ Based on studies comparing combined cholecystectomy and fistula closure to enterolithotomy alone, some authors advocate that simple extraction of the stone is adequate treatment for most patients as this procedure is associated with less complications, lower mortality rates and the fact that recurrence of gall stone ileus is a rare event. ${ }^{13-15}$ In this report, patient was treated with simple stone extraction without any intervention on the fistula. During 1 year follow up, our patient has not developed symptoms or required a second surgery due to development of associated pathology.

\section{CONCLUSION}

For optimized outcome the medical and perioperative management and type of surgery are tailored to the condition of the patient. An initial endoscopic effort should be generally performed. In cases requiring surgical intervention, we recommend the simple extraction of the stone without fistula repair.

\section{Competing interests}

The authors declare that they have no competing interests.

\section{Acknowledgement}

There are no acknowledgments.

Copyright@ 14 Oct, 2019.

\section{REFERENCES}

1. Yang D, Wang Z, Duan ZJ, Jin S. Laparoscopic treatment of an upper gastrointestinal obstruction due to Bouveret's syndrome. World J Gastroenterol. Oct $28 ; 19(40): 6943-6$.

2. Cappell MS, Davis M. Characterization of Bouveret's syndrome: A comprehensive review of 128 cases. Am J Gastroenterol. 2006 Sep; 101(9):2139-46.
3. Nabais C, Salustio R, Morujao I, Sousa FV, Porto E, Cardoso C, et al. Gastric outlet obstruction in a patient with Bouveret's syndrome: A case report. BMC Res Notes. 6:195.

4. Iancu C, Bodea R, Al Hajjar N, Todea-lancu D, Bala O, Acalovschi I. Bouveret syndrome associated with acute gangrenous cholecystitis. J Gastrointestin Liver Dis. 2008 Mar; 17(1):87-90.

5. Mavroeidis VK, Matthioudakis DI, Economou NK, Karanikas ID. Bouveret syndrome-the rarest variant of gallstone ileus: a case report and literature review. Case Rep Surg. 2013: 839370.

6. Gajendran M, Muniraj T, Gelrud A. A challenging case of gastric outlet obstruction (Bouveret's syndrome): A case report. J Med Case Rep.5:497.

7. Koulaouzidis A, Moschos J. Bouveret's syndrome. Narrative review. Ann Hepatol. 2007 Apr-Jun; 6(2):8991.

8. Yu CY, Lin CC, Shyu RY, Hsieh CB, Wu HS, Tyan YS, et al. Value of CT in the diagnosis and management of gallstone ileus. World J Gastroenterol. 2005 Apr 14; 11(14):2142-7.

9. Ayantunde AA, Agrawal A. Gallstone ileus: diagnosis and management. World J Surg. 2007 Jun; 31(6):12927.

10. Doycheva I, Limaye A, Suman A, Forsmark CE, Sultan S. Bouveret's syndrome: Case report and review of the literature. Gastroenterol Res Pract. 2009; 2009:914951.

11. Nickel F, Muller-Eschner MM, Chu J, von Tengg-Kobligk $\mathrm{H}$, Muller-Stich BP. Bouveret's syndrome: presentation of two cases with review of the literature and development of a surgical treatment strategy. BMC Surg. 13:33.

12. Katsinelos $P$, Dimiropoulos $S$, Tsolkas $P$, Baltagiannis S, Kapelidis P, Galanis I, et al. Successful treatment of duodenal bulb obstruction caused by a gallstone (Bouveret's syndrome) after endoscopic mechanical lithotripsy. Surg Endosc. 2002 Sep; 16(9):1363.

13. O’Neill C, Colquhoun P, Schlachta CM, Etemad-Rezai R, Jayaraman S. Gastric outlet obstruction secondary to biliary calculi: 2 cases of Bouveret syndrome. Can J Surg. 2009 Feb; 52(1):E16-8.

14. Brennan GB, Rosenberg RD, Arora S. Bouveret syndrome. Radiographics. 2004 Jul-Aug; 24(4):1171-5.

15. Thompson RJ, Gidwani A, Caddy G, McKenna E, McCallion K. Endoscopically assisted minimally invasive surgery for gallstones. Ir J Med Sci. 2009 Mar; 178(1):85-7. 


\begin{tabular}{|c|l|l|l|}
\multicolumn{4}{|c|}{ AUTHORSHIP AND CONTRIBUTION DECLARATION } \\
\hline Sr. \# & \multicolumn{1}{|c|}{ Author(s) Full Name } & \multicolumn{1}{c|}{ Contribution to the paper } & Author(s) Signature \\
\hline 1 & Marrium Gul & $\begin{array}{l}\text { Data collection, literature } \\
\text { search, manuscript writing. } \\
\text { Data collection, literature } \\
\text { search, manuscript writing. }\end{array}$ \\
\hline 2 & Irfan Qadir & \\
\hline 3 & Muhammad Qasim Butt & \\
\hline
\end{tabular}

